\title{
On the MUVE or in decline: Reflecting on the sustainability of the Virtual Birth Centre developed in Second Life
}

\author{
Sarah Stewart \\ Otago Polytechnic \\ Deborah Davis \\ University of Canberra
}

\begin{abstract}
Pressures in terms of the availability of quality, real-life clinical experiences for students have resulted in increased interest in the use of simulation in a variety of healthcare disciplines. Te wahi whanau: The birth place is a Virtual Birth Centre (VBC) that was created in Second Life in 2009 as part of the Second Life Education in New Zealand (SLENZ) initiative. It was introduced to midwifery students at two New Zealand polytechnics, with the aim of exposing the students to a birth centre environment and providing them with an opportunity to practise midwifery through immersion and engagement in a number of clinical scenarios. It has been just over two years since the development of the VBC, yet it is no longer used in the midwifery programs in which it was introduced. Using the VBC as a case study, we recount its development and critically reflect on the factors impacting on its ongoing utilisation. We believe our reflections offer useful insight into issues relating more broadly to the sustainability of MUVE-based teaching and learning projects and initiatives.
\end{abstract}

\section{Introduction}

The teaching and learning landscape in tertiary education institutions is rapidly changing. Learning is no longer confined to business hours, specific geographical regions or the physical space of the classroom. In healthcare education, quality clinical placements are becoming increasingly difficult to secure, and in midwifery in particular, the predominance of obstetric environments (tertiary hospitals) and intervention in childbirth means that it is difficult to provide midwifery students with experience in normal birth in low-technology settings such as birth centres (Leap, 2002; Leap, Barclay \& Sheehan, 2003; Tracy, Barclay \& Brodie, 2000). To meet the needs of the 21st-century learner and the vagaries of the healthcare environment, institutions are looking increasingly to e-learning technologies and other simulated clinical experiences to replace or augment real-life clinical practice experiences. Threedimensional multi-user virtual environments (3D MUVEs or simply MUVEs, as they are referred to in this article), while not a panacea for these problems, offer us some exciting opportunities for education in midwifery and other healthcare disciplines.

In 2009, we (both midwifery educators) submitted a proposal to the Second Life Education in New Zealand (SLENZ) group to be included as one of two pilot studies in a project funded by the New Zealand Tertiary Education Commission. We were 
successful in our application, and Te wahi whanau, the Virtual Birth Centre (VBC), was developed in Second Life, encompassing a range of teaching and learning strategies. The environment and strategies were trialled in undergraduate midwifery programs at two polytechnics located on the South Island of New Zealand. The development of the project was resource intensive, absorbing large quantities of funding, time and energy over a 12-month period. Two years later, the VBC gathers virtual cobwebs as it sits, relatively unused, on its original site within Second Life.

This article describes the development of the VBC, the pedagogical strategies employed and the learning outcomes developed for the project. Drawing on informal discussions with professional peers who have an interest in MUVEs and healthcare education, on the results of the project's formal evaluation, as well as on our own reflections on the experiences of developing the $\mathrm{VBC}$, this article offers commentary and critical reflection on issues relating to the sustainability of MUVE-based teaching and learning innovations such as the VBC. Innovation in teaching and learning is often driven by educators who have limited e-learning and/or technical knowledge and experience, but are motivated to explore creative solutions to the pedagogical problems they encounter in their practice. This was the situation with the project reported here, in which excitement over the novelty and possibilities of a new technology obscured concern for longer-term issues like sustainability.

In this article, we explain, in retrospect, the importance of having a strategy in place for moving a successful MUVE-based teaching and learning innovation beyond experimental or pilot status to become an embedded component of the curriculum. While the VBC was developed specifically for use in the discipline of midwifery, the reflections offered here are likely to have broad applicability and be able to drawn upon to inform aspects of educational MUVE projects across the disciplines as they relate to innovation and sustainability. A case study such as this can sometimes be more illuminating than an article dealing abstractly with theories of innovation or sustainability.

\section{Teaching and learning in virtual realities}

Users of MUVEs - also known as virtual worlds - create digital representations of themselves called avatars, which they use to interact in real time with one another in a 3D virtual environment. Emerging from multi-user online games, these virtual landscapes of interacting individuals have been called the 'natural playgrounds' of young adult learners (Hansen, 2008), offering engaging, effective, rich and immersive learning experiences (Johnson, Vorderstrasse \& Shaw, 2009). In terms of teaching and learning, MUVEs lend themselves to strategies that focus on interaction (with others and the environment) and role-play (Salt, Atkins \& Blackall, 2008), and they are able to be used in ways that position students as active participants rather than passive observers (C. Johnson et al., 2009). Simulation and role-play are established teaching and learning strategies in health education, wherein it is used to give students opportunities to develop and gain confidence in exercising a variety of clinical skills within a safe, low-risk or risk-free environment (Seropian, Brown, Gavilanes \& Driggers, 2004; Birch et al., 2007; Haigh, 2007; Lathrop, Winningham \& VandeVusse, 2007; Dow, 2008). Once they have mastered basic navigation skills in the virtual environment, individuals exploring these environments can gain a sense of presence or 'really being there' (C. Johnson et al., 2009). This sense of presence has been associated with improved learning and performance (Witmer \& Singer, 1998), as well as with 
increased knowledge transfer from the virtual world to the real world (Slater, Linakis, Usoh \& Kooper, 1996).

A range of healthcare education resources ('builds') and teaching and learning strategies have been developed in MUVEs such as Second Life. Most of these focus on general health promotion and education for lay residents, and some also contribute to the education and training of health professionals, both pre-service and in-service (Beard, Wilson, Morra \& Keelan, 2009). The US Centres for Disease Control and Prevention (CDC), for example, have a substantial presence in Second Life in the form of CDC Island (Boulos, Hetherington \& Wheeler, 2007). This site contains informative displays and offers opportunities for users to interact with various virtual objects (e.g. microscopes to learn about bacteria) as well as to network with one another by joining discussions and focus groups. Another Second Life build that aims to raise awareness about a specific health issue can be seen in the University of California, Davis Medical Centre's Virtual Hallucinations simulation (Yellowlees \& Cook, 2006). This build simulates the auditory and visual hallucinations that many patients suffering from schizophrenia experience, with the aim of promoting greater understanding and empathy for those with the condition as well as to disseminate related health information.

Strategies targeted towards the education of health professionals range from those that involve the running of in-world symposia or seminars (Kessler \& Rowell, 1998) through to those that provide the opportunity engage in role-play with peers and/or with virtual patients and objects (e.g. X-rays) with the aim of improving communication, diagnosis and/or other generic and specialised clinical knowledge and skills (Hansen, 2008). One such build that is particularly relevant to the nursing and midwifery discipline is the postpartum haemorrhage clinical scenario developed by academics from the Boise State University in the US and The University of Auckland in New Zealand (Honey, Diener, Connor, Veltman \& Bodily, 2009).

The body of available research literature on the use of MUVEs in the education of health professionals is in its early stages. Most of the papers and articles published to date in this area are descriptive (e.g. Skiba, 2007) or exploratory (e.g. Rogers, 2011), with those that are evaluative often reporting on pilot studies (e.g. Wiecha, Heyden, Sternthal \& Merialdi, 2010) and/or studies with small sample sizes (e.g. Blyth, Loke \& Swan, 2010; McCallum, Ness \& Price, 2010). There is a dearth of empirical evidence comparing the outcomes of MUVE-based teaching and learning strategies with those of traditional methods. In our searches, the only significant study focussing on the education of health professionals we located that compared traditional teaching and learning methods with teaching and learning using virtual-reality environments was the one by Lok et al. (2006). That study, however, involved the projection of a life-sized virtual patient on a wall rather than the use of a MUVE.

\section{Sustainability of educational innovations in MUVEs}

While a number of educational initiatives involving MUVEs are reported in the literature, as mentioned above those reports are largely descriptive in nature, perhaps reflecting the relative infancy of MUVE-based education as a field of scholarship. This leaves a gap in the literature for research providing evidence of the effectiveness of MUVE-based teaching and learning innovations (vis-à-vis traditional methods) - and more importantly for our purposes, the sustainability of such innovations. This is somewhat surprising given the considerable resources (financial, expertise and time- 
related, etc) that have been and are being invested into these initiatives. Holt and Segrave (2003, p. 227) claim that "The age of local thinking and action (by unit team, course, school or faculty) has... given way to a more strategic institution-wide approach". Although this could well be the case for e-learning in general, in particular that involving older and more mature technologies like learning management systems (LMSs), the assertion may not necessarily hold true for teaching and learning innovations involving newer or more nascent technologies such as MUVEs. The Summer 2010 snapshot of virtual world activity in UK universities and colleges authored by Kirriemuir (2010a) suggests that while some MUVE projects are thriving and becoming integrated within the curricula of the relevant programs, the use of MUVEs is still largely a niche activity rather than representing mainstream practice at institutions. We can look to the broader literature on e-learning to help inform us on the issue to some extent; however, there are discrete and unique issues that impact on the sustainability of teaching and learning initiatives as they apply to MUVEs specifically.

Sustainability of any initiative is closely related to adoption. While it is beyond the scope of this article to address adoption of innovations in detail, it is noteworthy that a number of factors have been found to impact on adoption (and therefore sustainability) of e-learning innovations. These include perceived value to the user, accessibility, digital literacy and competence with the technology, motivation, and effectiveness of the innovation (Eley, Fallon, Soar, Buikstra \& Hegney, 2008; Kelly, Coburn, Hegarty, Jeffrey \& Penman, 2009; Stewart, 2006; Yu, Chen, Yang, Wang \& Yen, 2007). Drawing on a survey of higher educators across Australia and New Zealand, Dalgarno, Lee, Carlson, Gregory and Tynan (2011b; see also Dalgarno et al. 2011a; Lee, Dalgarno, Gregory, Carlson \& Tynan, 2011) discuss the technical and policy hurdles that teaching staff must negotiate to overcome barriers to the utilisation of MUVEs in universities. These include technological issues, support issues, funding and time, usability and familiarity, equity and ethical issues, inherent limitations of virtual worlds, acceptance of virtual worlds, and management and planning.

For some time now, educators have expressed concern about the need to improve the sustainability of e-learning innovations, identifying a variety of obstacles and potential solutions in this regard (Andrews, Smyth, Tynan, Vale \& Caladine, 2008; Gunn, 2011; Holt \& Segrave, 2003; Wiles \& Littlejohn, 2003). Andrews et al. (2008) point to the inability of teaching staff to alter their pedagogical approaches to make the best use of available technologies, and the lack of infrastructure within institutions to support the integration of those technologies. Addressing the issue of media-rich technologies more broadly in the Australian context, they suggest that these factors contribute to a situation in which institutions have been largely unsuccessful in implementing the technologies in sustainable and scalable ways. Wiles and Littlejohn (2003) suggest that the major challenges standing in the way of sustainability of e-learning innovations relate to cultural and social rather than technical issues. They echo the sentiment that educators moving into e-learning need to rethink their pedagogical approach, reversing their usual processes by prioritising learning design over content development. They also emphasise the importance of sharing and reusing resources, suggesting that this can be best facilitated through the cultivation of communities of practice.

A comprehensive report by Attwell (2004) addresses the sustainability of e-learning from a variety of perspectives, including learning platforms and software, institutional 
responses, materials, pedagogical approaches, and teacher skills. The report concludes with a sustainability 'checklist' featuring items such as the sharing and reuse of materials, a planned approach to developing and reviewing strategies, frameworks for professional development, integration of services, embedding of e-learning within curricula, and developing partnerships and networks. Yet another valuable resource is the UK Joint Information Systems Committee (JISC) 'good practice guide' on sustaining and embedding innovations (Chatterton, 2011). This guide aims to support those involved in innovative projects to embed them into practice by providing useful information and resources in a number of areas: changing people and culture, influencing organisational change, embedding or aligning innovations, creating usable tools and resources, and commercial and open approaches to innovation.

In a report for the Australian Flexible Learning Framework, Callan and Bowman (2010a, p. 14) identify seven factors that influence the sustainability of e-learning innovations, which they describe as follows:

- Strategy. Vision, values, strategy and planning that underpins e-learning as a core feature of the current and future business.

- Senior leadership. Leadership at the executive team level that supports and champions e-learning, and promotes the use of e-learning as a tool for cultural and structural change.

- Resourcing. Resourcing that supports initial e-learning initiatives and subsequent efforts to embed across the organisation; this could be internal or external funding (e.g. [Australian Flexible Learning] Framework funds).

- Local e-champions. Experts in instructional design and the application of new technologies who promote and support others to review and introduce new ways of delivering training to clients.

- Technological supports. Hardware and software support together with reliable and robust network facilities.

- People supports. Competent and supportive IT staff who share the vision and strategic goals of promoting e-learning solutions across various parts of the business, including training.

- Make the business case. A continued business focus that promotes the business case upon how e-learning benefits the organisation around a wide range of areas, including more flexible training, delivered more consistently, of higher quality, and with reduced time and financial costs.

While a number of sustainability frameworks and guides exist, most have at their core several key elements, and these are captured succinctly in Callan and Bowman's framework. We have therefore used their framework later in this article to structure our reflections on the VBC and its sustainability.

Concern for sustainability reflects a desire to maximise the gains achieved by innovations beyond the life of the project. Gunn (2011) gives an overview and synthesis of the literature addressing the challenges and proposed solutions for sustainability of e-learning initiatives, and in doing so makes an astute observation with regard to the extant literature (p. 509):

The challenges of turning funded projects from e-learning innovations into sustainable products and services have featured in the higher education literature for more than forty years. Various guidelines and strategies designed to facilitate the process have been developed and tested, key challenges are identified and 
critical success factors proposed, yet the problem persists in more or less original form, suggesting that most of the advice has been lacking in some respect.

Another problem that Gunn points to is a lack of published evidence supporting strategies for sustainability. The literature is replete with 'good ideas' and 'works in progress' (see, for example, Lucas, 2006; Wiles \& Littlejohn, 2003) but seriously lacking in hard evidence and systematic retrospective analysis. This is where our case study seeks to make a contribution. It presents an in-depth reflective analysis - a 'postmortem', of sorts - of an e-learning innovation, focussing particularly on the issue of sustainability. As Gunn argues, the sustainability of e-learning innovations continues to be a problem despite published literature providing generic advice, strategies, guides and checklists. While there is something to be gained from the literature, this implies that sustainability may be significantly impacted upon by the situations and circumstances surrounding individual projects. Case studies (and a review of case studies, as Gunn proposes) offer an opportunity to examine the innovations within the bounds of their unique contexts. In the next section, we provide an overview and description of the VBC project before proceeding to critically reflect on the sustainability aspects of the project.

\section{Development of the Virtual Birth Centre}

In Australasia, the difficulty of organising quality clinical placements for healthcare students is escalating (Australia's Health Workforce Online, 2010). Clinical placement shortages are reaching crisis point in some quarters, with at least one university in New South Wales in 2011 anticipating being unable to provide its nursing students with the clinical experiences necessary to complete their degree program (McGilvray, 2011). In midwifery, increasing 'medicalisation' of childbirth (rising rates of caesarean section and other obstetric interventions) means that it is also proving challenging to provide midwifery students with clinical placements in settings that help them learn about their role in the promotion of physiological birth. Childbirth is increasingly moving to tertiary hospital maternity units, with environments that traditionally promoted physiological birth such as home and birth centres becoming harder to access (for both childbearing women and midwives).

We have thus seen a gradual eroding of avenues for student midwives to learn and practise the skills that form the foundations of practice in the profession. The landscape of tertiary education is also changing as institutions embrace flexible modes of course delivery for a variety of reasons. Learning is no longer confined to the physical location of the classroom or to set 'office hours', as we are having to reach out to students who may be accessing courses from a variety of locations and at times more convenient to them. The midwifery programs at the two New Zealand institutions in which this project was implemented were moving towards flexible delivery modes in order to support students studying midwifery at a distance. This largely meant migrating existing courses to an Internet-based LMS, with the use of synchronous web conferencing for tutorial support.

This was the professional, clinical and educational context motivating the development of the VBC. Based in Second Life, Te wahi whanau: The birth place (http:/ / www.slurl.com/secondlife/Kowhai/82/213/35) was designed to be a safe, risk-free environment in which for student midwives to hone their clinical problemsolving and decision-making skills through engagement with a variety of 
physiological birth scenarios, as well as for them to gain exposure to a birth centre environment, an experience that would otherwise not be available to them in real life. The VBC was also intended to provide a (virtual) venue where geographically dispersed students could come together to work collaboratively and form a community of learning with their peers.

\section{Transparency and openness of the project and developed resources}

In the spirit of open access, the VBC project was created under a Creative Commons 'Attribution-Share Alike 3.0 New Zealand' licence (Winter, 2010). This licence allows for sharing, commercial use and modification on the proviso that the resulting work is similarly licensed (see Creative Commons, n. d.). This means that the VBC can be copied to any other Second Life location, or exported to another compatible virtual world platform, to be used and/or modified for any purpose. In addition, the project team shared, on a WikiEducator site (http://www.wikieducator.org/The_virtual_ birthing_unit_project), all supporting materials and resources created as part of the project, such as lesson plans, Second Life orientation packages and scenario information. Weekly postings about the project's development were also published on the SLENZ blog (http://slenz.wordpress.com/) in the interest of making the project and all of its processes transparent to the wider community. It was hoped that this approach would increase the impact of the project beyond the pilot phase by contributing to an emerging community of practice in ways that would assist those embarking on similar acivities, and by encouraging others to build on the work done as part of the project.

\section{VBC project phases}

\section{Phase 1: Birth environment}

The VBC was developed in Second Life to support undergraduate midwifery education, and was introduced to student midwives in two baccalaureate programs in New Zealand. The development of the VBC began in 2008 and consisted of two phases. The first phase involved building an 'ideal' birth environment within Second Life based on design features known to support physiological birth in real life (Fahy, Foureur \& Hastie, 2008). A decision was made to construct a model of a traditional building as opposed to creating a metaphorical or fantastical space. The VBC features two clinicstyle rooms for consultations, and on the second floor, a large meeting space. The ground floor contains a living area and kitchen for the use of the childbearing woman and her supporters, an office and utilities for staff, as well as two large birthing rooms complete with a double bed, ensuite, birth pool, and props to support a woman in active labour (e.g. things to lean on such as mantles, and exercise balls to sit on). Each of the birthing rooms has access to a private outdoors area. Many of the objects in the VBC are linked to evidence-based information located on the WikiEducator site.

The aim of this first phase of the project was to encourage midwifery students to think about the effect of the environment on the physiology of normal labour and to provide them with evidence-based information on practices that promote physiological birth (e.g. water immersion) in an applied, authentic context. A number of learning activities were developed to assist students in focussing on the birth environment and its features. These included an assignment requiring them to produce a written piece comparing and contrasting the birth environment of the VBC with other birth environments they had encountered in real life (e.g. the tertiary maternity hospital), 
and a tutorial conducted within the VBC where the design of birth units was discussed following a tour of the VBC. Specifications of these and other learning activities can be found on the project's WikiEducator site (http://www.wikieducator.org/The_virt ual_birthing_unit_project\#Learning_activities). These activities were voluntary and formative, and they did not contribute to the students' grades. They were, however, designed to complement the subjects undertaken by the students in the first year of their program, and to contribute to the existing objectives for the first-year clinical practice subject, in particular:

1. Demonstrate an understanding of childbirth as a normal life event which occurs within diverse social and cultural contexts;

2. Discuss the impact of the underpinning philosophies of midwifery on the childbirth experiences of women and the development of midwifery knowledge.

\section{Phase 2: Clinical role-playing scenarios}

The second phase involved the development of clinical scenarios based on the format of two students working together as 'midwife' and 'mother' in role-plays centred around physiological birth. A total of five scenarios or 'scenes' were developed, each depicting different stages and aspects of labour and childbirth: the beginning of labour, early labour, established labour, birth, and the first hour following birth. The scenarios take place in the upstairs area of the VBC. In carrying out the role-plays, each character must access information and resources relevant to him/her such as a pregnancy suit and a script for the 'mother'. This script provides the student playing the mother with an outline of the information she should impart and the behaviours she should enact during the scenario. The student playing the midwife can download the antenatal record for the childbearing woman, providing him/her with information on the woman's medical and obstetric history and her current pregnancy. Each character is supplied with a heads-up display (HUD) and scripted animations for use in the scenario allowing for actions such 'change position' for the labouring woman and 'provide comfort' or 'check fetal heart sounds' for the midwife.

The student who plays the part of the midwife is required to assess, plan and act on the information provided and the behaviour exhibited by the 'mother'. At the end of each scenario, the 'midwife' receives feedback from the 'mother', and is able to selfassess his/her own performance against predefined criteria developed by the midwifery educators. The 'mother' is asked to focus on the following in her feedback to the 'midwife':

- How easy was the midwife to talk to?

- Was the midwife sensitive to your needs?

- How satisfied were you with the information the midwife gave you?

- How satisfied were you with the way the midwife listened and responded to your questions and concerns?

- Were your decisions respected by the midwife?

- How satisfied with you with the action plan that the midwife developed with you?

The student playing the midwife is also required to document his/her actions and submit them to lecturers for feedback. The scenarios are based on the core competencies and standards of the profession as defined by the Midwifery Council of New Zealand (2010), and on real-life clinical situations. The feedback mechanisms used by the lecturers were based on the professional processes developed by the New Zealand College of Midwives (n. d.). 
The scenario-based learning activities developed in the second phase are aimed at student midwives in the second and third years of their program and were voluntary, supplementing rather than replacing existing teaching and learning strategies and reallife clinical experiences. Again, they were designed to contribute to existing learning objectives:

1. Demonstrate an understanding of the role of the midwife in the normal childbirth process;

2. Demonstrate effective, evidence-based midwifery practice guided by a sound knowledge base;

3. Demonstrate an understanding of the significance of concepts of accountability, responsibility and independent practice as they relate to midwifery practice in New Zealand.

All resources used within the clinical scenarios continue to be available on the aforementioned WikiEducator site.

\section{Evaluation and ongoing utilisation}

A formal evaluation of the two implementations carried out as part of SLENZ was undertaken by an independent group (Winter, 2010). Using a case-study approach, the evaluation sought to answer the following questions (p. 4):

- How and to what extent do MUVEs such as Second Life offer enhanced learning for New Zealand tertiary students?

- What could have been done better during the design, development and delivery of the two pilot learning activities in Second Life?

- What worked well during the design, development and delivery of the two pilot learning activities in Second Life?

- What good practice can be identified that may help others design, develop and deliver learning experiences in MUVEs?

Data were gathered from students, project team members and educators through face to face interviews and focus groups, and also during an in-world meeting. The evaluation demonstrated that student midwives particularly valued the opportunity to role-play in the VBC without the stress of having to perform in real-life situations in front of actual patients and practising midwives and/or in the presence of lecturers and peers. A rather surprising result was that it was the junior students who valued the VBC the most. They saw it as an authentic and immersive orientation to their reallife clinical placements, allowing them to become familiar with the clinical environment and practise their skills, making mistakes along the way as they did so yet continuing to feel safe. Both the midwifery lecturers and students experienced difficulties with the technology, however - computer capabilities, Internet bandwidth limitations and institutional firewalls prevented them from fully engaging despite much effort having been put in early on in the project to address many of these issues. Many of them found navigation in Second Life difficult to master, requiring a longer orientation period than had been allowed for. The main recommendations arising from the evaluation were as follows (Winter, 2010, p. 6):

- Establish a larger development team, and adopt a 'sprint'-based development process; 
- Ensure that developers and educators spend time together to familiarise themselves with the requirements of each other's disciplines;

- Establish close collaboration with institutions' IT departments to ensure that learners can have fully functional access to builds within institutions;

- Establish champions of the project at a senior level in each participating institution;

- Communicate with students regarding ICT requirements and expected broadband usage to run the builds at home, and expectations in terms of participation and learning outcomes;

- Provide a thorough, compulsory orientation to the virtual world;

- Ensure that each stage of each build incorporates highly interactive and engaging activities for learners.

Despite a largely favourable reception, two years later, the VBC lies relatively empty and dormant. It is no longer used by the institutions at which it was pilot tested, and to our knowledge, there has been no ongoing interest from other educational institutions in New Zealand or elsewhere wishing to adopt the environment and integrate it into their programs. This is in spite of efforts to introduce and promote the project to midwifery education audiences through a variety of forums (Stewart \& Davis, 2009) and the VBC build being copied numerous times. Using the VBC as a case study, we now turn our attention to the issue of sustainability of educational innovations in a MUVE.

\section{Reflecting on sustainability of the VBC}

Callan and Bowman's (2010b) sustainability framework provides a useful way for us to structure our critical reflections on the VBC in terms of its sustainability. In the commentary that follows, we draw on our own experiences as well as anecdotal feedback from peers within our professional networks known to have an interest in the VBC specifically or the use of MUVEs in midwifery education more broadly. We acknowledge that the perspective of other relevant stakeholders (senior managers, IT support staff, etc) is missing from this analysis, but nonetheless consider that our perspective as frontline educators makes an important, and hopefully worthwhile, contribution to the field.

\section{Strategy}

The VBC project was funded by the Tertiary Education Commission in New Zealand and involved a team of researchers and educational developers from several tertiary education institutions. While the environment, activities and resources were piloted in midwifery programs at two New Zealand polytechnics and therefore obviously required the cooperation of staff - including management staff, IT support staff and midwifery teaching staff - at those sites, the project leadership originated from outside of those institutions. This meant that while the particular organisations involved may have had a vision and strategy for the development of e-learning innovations at the institutional level (indeed they did), the VBC project was not integrated as part of this strategy; it sat somewhat awkwardly to the side as a discrete, albeit potentially interesting, innovation.

The lack of integration of this project in the overall e-learning strategy of the participating institutions may also reflect the novelty of (and suspicion towards) virtual reality technologies in the educational setting. The focus of the institutional 
strategy, at least from our perspective as educators within one of those institutions, was on more mainstream e-learning technologies, including the use of web-based LMSs to serve as a replacement for face to face teaching. A number of authors (Attwell, 2004; Gunn, 2011) have stressed the importance of devising a high-level strategy for the implementation, integration and review of e-learning initiatives at institutions. While e-learning represents an array of teaching and learning strategies and technologies, innovations developed for MUVEs are often (though not always) considered niche, and thus tend not to be included as part of this broader e-learning strategy (Kirriemuir, 2010a).

\section{Senior leadership}

Leadership at the executive level has been identified as one of the central factors impacting on the sustainability of e-learning innovations. This leadership may take a variety of forms, depending on the nature of the organisation (Callan \& Bowman, $2010 \mathrm{~b}$ ). While the VBC project was led by a capable and visionary project team, as mentioned before this team was largely comprised of 'outsiders' external to the implementation sites. Senior leaders at the sites were supportive, and this support was necessary to ensure that the necessary adjustments could be made to the IT software, hardware and infrastructure to accommodate the use of Second Life. It was also needed to ensure that the relevant teaching staff and students could be introduced to and encouraged to use the VBC, and that these individuals would be allowed to participate in the project evaluation. However, while the project had the cooperation of the senior leaders, it was not embraced or promoted by them, nor was it supported by them beyond the bare minimum required to facilitate project completion. The midwifery teaching staff who participated in the project did so on a voluntary basis, and this work was in addition to their usual responsibilities. Managerial support for e-learning innovations has been identified as critical to their success and sustainability (Gunn, 2011). In a case study of pedagogical innovation and the use of educational technologies by academic staff at an Australian university, Tynan and Lee (2009) highlight the importance of both a top-down and bottom-up approach to innovation. Leaders should provide a vision, incentives, policies, infrastructure and funding, while staff at all levels of the organisation need to commit to embracing change. Leadership, however, needs to be flexible and open enough to allow innovation without stiffling it in bureacraatic processes.

\section{Resourcing}

Developing teaching and learning strategies within MUVEs is resource intensive (Dalgarno et al., 2011b; Kirriemuir, 2010a, 2010b; Lee et al., 2011). Many institutions may be unwilling to invest in e-learning modalities that are considered more marginal than mainstream, or that they may see as being cutting-edge or experimental, and in these situations outside funding sources are important. In Callan and Bowman's (2010b) review of institutions that received funding from the Australian Flexible Learning Framework, they found that external funding permitted more risk taking and opportunities to trial cutting-edge technologies than internal funds would allow. The VBC was funded by the Tertiary Education Commission of New Zealand, and without doubt, would not have been possible without this funding. The funding covered the costs of overall project management, as well as of bringing into the project expertise in midwifery curriculum design, MUVE development and learning design. Considerable time and expertise was donated in a voluntary capacity by numerous individuals. The 
collaborative (and national) nature of the project brought together knowledge, skills and experience from a variety of areas that may not be available in any one single organisation. The project was funded to explore the way MUVEs could be used in education in New Zealand, and did not explicitly aim to develop opportunities that were sustainable in a given institution.

Once developed, the complex teaching and learning strategies in the MUVE require maintenance and updating, and without ongoing funding or commitment, may quickly become obsolete or inoperative. The ability of innovations to become sustainable after project funding has been depleted is a common, recurring concern (Gunn, 2011; Tynan \& Lee, 2009). Along with unrealistic timeframes or expectations of funders, this contributes to a situation whereby, according to Gunn (2011, p. 509), "many projects with strong educational potential fail to find the means to continue beyond the funding phase, and a low return on investiment is achieved". In our project, there was no ongoing funding provided to maintain or further develop the VBC on its original Second Life site, though the open-access arrangements and Creative Commons licensing used provided a means for others to obtain a copy of the VBC for reuse and/or further development on their own sites.

Unfortunately, we have not formally tracked the number of copies that have been made of the VBC to date, though we are advised by our developer that it is in the vicinity of 30 . We have no way of knowing for what purposes the copies were made, and some may have perfomed the copying in order to obtain particular artefacts rather than to use the VBC environment in its entirety for the purposes it was originally intended. We are aware of one educator in the USA who copied the VBC some time ago, and has since developed and repurposed it into an aged care facility for training nurses. Another aspect of the open-access philosophy of the project involved storing all of our planning, curriculum, teaching and learning documents on WikiEducator. A midwife educator in the UK who has built another birth facility in Second Life reports that she used our planning framework to guide the development of her build (Bailey, 2012). Two midwifery educators in the UK and USA have expressed intentions to integrate the VBC into their teaching, but at the time of writing of this article have yet to actually do so. They have told us that this is because they have not had the time to develop their skills to a point where they are confident enough to support students in Second Life. They also do not have access to adequate time and funding to customise the VBC to fit their own context. Open source, open access and the development of shared learning repositories is a key feature of the works addressing sustainability of e-learning innovations (Attwell, 2004; Chatterton, 2011; Holt \& Segrave, 2003). Attwell (2004) points out that a shared approach to resources, especially across a variety of institutions and disciplines, calls for a major change in academic culture. Open access has the potential to aid others in resourcing their projects and to contribute to sustainability, but resources are not the only barrier to developing and sustaining innovations in the MUVE.

\section{Local e-champions}

Local champions play a pivotal role in raising awareness of e-learning technologies and offering local support for others wishing to integrate those technologies into their own instructional design and teaching practice. The VBC was supported by a number of midwifery e-champions whose enthusiasm for the potential of the project was greater than their technological expertise. Supported by SLENZ, they did gain a level 
of expertise in the MUVE and in learning design for this environment. They were then able to provide support, training and assistance to their peers and to the student midwives involved in the project. At the local level, the project was largely driven by these champions, of whom there were three at one of the sites and one at the other. Sadly, by the end of the funded project two of the local champions at one site had left that institution. While both institutions were embarking on the development of a new, joint curriculum heavily reliant on e-learning technologies, the VBC was not integrated into the new curriculum. Besides the loss of the two local champions, a number of factors contributed to this, including the workload involved in developing a new curriculum with a limited budget and within a very tight timeframe, which left staff with little energy or opportunity to consider cutting-edge innovations. While increased efficiencies have been central to the argument for adopting e-learning technologies, Tynan and Lee (2009) note that these efficiencies have not necessarily been realised, as this work is inherently labour intensive. They comment, "Institutions often fail to recognise that there is a hidden cost in terms of additional, often unpaid, teaching hours in the development and maintenance of online materials" (p. 100).

These sorts of innovations are often driven heavily by the energies and commitments of individuals who are, in effect, the leaders and local champions for the innovation. Often, the work involved in developing teaching and learning projects in MUVEs is taken on by those involved on top of their regular, day-to-day responsibilities, and is sustained by their enthusiasm for the project (Dalgarno et al., 2011b; Kirriemuir, 2010b; Lee et al., 2011). The risk to an institution with this approach is that the project or strategy is not sustainable beyond the commitment of the individuals, and the expertise they have developed may not have been shared with colleagues within the institution by the time they are ready to move on. E-champions are often early adopters, and their role in innovation is well recognised in the literature (Tynan \& Lee, 2009). However, many share concern for the sustainability of these innovations once their enthusiasm for a project has waned or they have gone on to other projects and roles (Gunn, 2011; Holtham, 2005; Tynan \& Lee, 2009). When an innovation relies heavily on local champions and is not otherwise integrated or supported at the institutional level, the innovation (and the relevant expertise) is lost to the institution upon the departure of the champions. This was a significant factor in the case of the VBC.

\section{Technological supports}

An integral component of the implementation and use of any e-learning technology is the technical support and network facilities available not only to end users, but also developers. Moreover, the development and implementation of MUVE-based teaching and learning resources and strategies calls for a collaborative approach between IT support and teaching staff - two groups who may not know a lot about each other's worlds and who may not be accustomed to working closely with each other. MUVEs demand certain hardware and operating system specifications and settings, require IT support so that they can be used effectively from networked computers, and consume significant amounts of network bandwidth. In our project, it took some time and a fair amount of negotiation for the VBC to function as desired on campus computers. At institutions that do not understand the benefits of MUVEs or view them with suspicion, it can be extremely difficult for educators to gain access for staff and students. This is particularly the case for staff employed in hospitals, where access to Internet sites and services are heavily restricted. One midwife colleague in the UK 
reported that she would like to use the $\mathrm{VBC}$ to expose midwives working in her tertiary hospital to a virtual birth environment, but that computing policies in force at the hospital made this impossible. Kirriemuir (2010b; see also Kirriemuir, 2010a) claims access issues seem to have been largely resolved for most users at UK universities and colleges; while that may be the case for those institutions - whose core business it is to deliver education courses - it is not necessarily so for other organisations involved in the delivery of practice-based or clinical education, such as health services and hospitals. There may be scope for the VBC to be used with qualified midwives and developed further to meet the ongoing professional development needs of this group, but difficulties gaining access for employed staff from hospital computers make this sort of development largely prohibitive.

\section{People supports}

Supporting educators to develop and embed e-learning technologies is important, and can be achieved in a variety of ways. Callan and Bowman (2010b) identify four different models for this in the institutions they reviewed: a central support model, a central unit linked to a network of e-champions, a partnering model with external expertise linked to e-champions, and a decentralised model. In the centralised model, a dedicated department with expertise in education, curriculum design and technical skills provides support to educators. The second model involves a smaller central unit that trains and supports e-champions in different areas of the institution, while the third involves the use of an external body to supply expertise and support to the echampions. Finally, the decentralised model involves individual units (e.g. departments, schools or faculties) providing their own support. Callan and Bowman (2010b) warn that this fourth model may enable motivated educators to develop their own e-learning innovations, but may not make the required support available to those who are less motivated or confident. While a number of broad approaches to supporting e-learning have been suggested in the literature (Attwell, 2004; Lucas, 2006), Gunn (2011) reminds us that there is very little in the way of empirical studies that provide us with concrete evidence as to the most effective support mechanisms. There may not be one best approach, as support needs differ between contexts and projects.

The VBC project was not part of an integrated approach to e-learning in the institutions where it was piloted. A team consisting of members with particular expertise was formed specifically for the purposes of the project, and through this team e-champions (the midwifery educators) were supported to interface directly with students and other teaching staff. These e-champions were also responsible for designing the teaching and learning strategies for use in the MUVE. This aligns somewhat with Callan and Bowman's third model (partnering model with external expertise linked to e-champions). One of the challenges with this model as we experienced it was in the communication between the e-champions who possessed considerable course content and professional knowledge (of midwifery in this case) but limited technical knowledge, and those who had the opposite - in other words, strong technical knowledge but limited content or curriculum design knowledge. For the discipline of midwifery and the MUVE learning environment it is unusual to find content, curriculum and technical knowledge in the one individual. This means that developers, designers and educators must be able to work together successfully to achieve a favourable outcome; good communication and strong leadership are crucial to this. Our project may well have severely faltered if it were not for the strong 
leadership, as we seemed to be communicating across a cavernous gap in understanding at times!

\section{Making the business case}

The business case for adopting and implementing new technologies at most institutions takes into account cost savings, efficiencies, improved productivity and/or added value to service users. Callan and Bowman (2010b) identify the business case as being essential in sustaining the focus on e-learning at any institution or organisation. Certainly, because of the resource intensitivity of the development of e-learning initiatives, especially those in MUVEs, support for investment in these initiatives would be difficult, if not impossible, to garner without a strong business case. Gunn (2011) identifies a sustainable business case as one of the key attributes of e-learning projects that have made a successful transition from innovation to sustainable practice. In the case of the VBC, our business case focussed on several key factors, including the opportunity to augment (rather than replace) real-life clinical practice experience, the opportunity to expose students to a birth environment that was not available to them locally in real life, and the opportunity for midwifery students to practise midwifery care in normal birth within a safe and risk-free environment. These have to do with adding value to an educational experience. Addressing the business case issue, Wiecha et al. (2010) highlight the importance of being able to identify the rationale for the use of a MUVE (in their case, Second Life) by answering the question, "'Why SL [Second Life]?' before it gets asked. In other words, it is critical to take advantage of the unique opportunities afforded by the virtual world to push the experience beyond what could be delivered via a website or a webinar" ('Overall lessons learned', para. 2).

A major barrier to making a strong business case for the inclusion of teaching and learning strategies in MUVEs is the dearth of solid empirical evidence demonstrating the effectiveness of this environment for learning when compared with traditional methods. In the absence of such evidence, it is very difficult to secure funding to develop or build on the work undertaken in the VBC.

\section{Discussion}

The VBC was developed as part of a funded project aimed at exploring the possibilities of Second Life for teaching and learning in educational institutions in New Zealand. The remit of the project was therefore broad, and the resulting resources novel and highly experimental. The project did not aim to produce high-level, generalisable empirical results attesting to the effectiveness of the environment for learning, nor did it seek to address issues pertaining to long-term sustainability of the resources within the institutions where they were piloted. It is, after all, unrealistic to expect a single project to address the multiplicity of issues that deserve attention in the MUVEs-for-education arena. Given its limited scope and aims, the VBC project was highly successful in giving rise to a wealth of learning and resources. In this article, we have retrospectively turned our attention to the sustainability of the project, which could be seen as being somewhat unfair; however, the goal of our critique is by no means to detract from or play down the project's success, but rather to attempt to further extend the learning and knowledge gained from the project. In the subsections that follow, we focus on the implications of our critical reflections for practice, policy and future research. Readers are invited to consider how the issues might apply to their own disciplinary contexts. 


\section{Building an empirical evidence base}

In healthcare education, a number of factors motivate us to consider MUVEs for teaching and learning purposes. As alluded to earlier, a lack of appropriate real-life clinical placements is one important driver, and the increasing move towards the provision of distance education via flexible delivery modes is another (Lok et al., 2006). The higher education market is becoming ever more competitive, with institutions reaching further afield geographically to attract students in an attempt to maintain the viability of their programs (Marginson, 2006). MUVEs provide a way to bring students and teachers together to engage in real-time, collaborative activities regardless of their physical location (Bower, Kennedy, Dalgarno \& Lee, 2011). They may also be used to facilitate learning that is at least as effective as, or in some respects even superior to, traditional forms of teaching and learning, though there is a lack of empirical evidence in this regard. This lack of evidence is one of the most critical factors impacting on the uptake and sustainability of MUVE-based teaching and learning initiatives.

Developing strategies for teaching and learning in a MUVE requires substantial effort on the part of both educators and students, who must acquire new skill sets specific to this environment. This does not simply involve mastering the particular tools or technology; it often also calls for drastically altering the pedagogical approach to a given subject area (Wiles \& Littlejohn, 2003). Staff, in particular, may be reluctant to put in the time and effort to develop these skills and invest in these strategies without seeing compelling evidence of their effectiveness. Without robust evidence it is also difficult to make a business case or argue that such strategies should be embedded into a program. It is unlikely that the drivers for the use of MUVEs in education outlined above will subside in the foreseeable future, and it is important that we do not miss important opportunities for enhancing the learning experiences of our students hence, investment in the necessary research is critical to generate the needed empirical support and to come up with evidence-based guidelines for MUVE-based teaching and learning.

This is complex and easier said than done, since teaching and learning strategies developed in this environment are as diverse and heterogeneous as they are in reallife environments. Salmon (2005) and others (e.g. Wiles \& Littlejohn 2003; Andrews et al., 2008) are critical of e-learning in the form it exists in many higher education institutions, suggesting that rather than reflecting true innovation, they tend to simply entail application of existing pedagogy to new media. Salmon argues that e-learning should instead be viewed in terms of the prospects it offers for radically rethinking education. MUVEs provide an opportunity for such pedagogical innovation, and research may need to extend beyond simplistic comparisons between MUVE-based and traditional methods of teaching and learning (Oliver, 2010). More and better consideration needs to be given to the new possibilities MUVEs open up that were not previously available through other means, including pre-existing technologies (Dalgarno \& Lee, 2010).

\section{Sharing of resources}

While SLENZ did not explicitly set out to develop projects that were sustainable into the long term within the institutions at which the pilot implementations took place, the project team's decision to make all resources developed freely and openly available to the wider community did have a favourable - even if unintended - impact on the 
sustainability of the VBC. Thus far we have identified a number of factors that have adversely affected the sustainability of the project at the institutional level; by contrast, the adoption of Creative Commons licensing and the commitment to an open educational resource (OER) philosophy were very positive in terms of helping to sustain the project beyond the borders of the institutions that were initially involved. The Creative Commons licensing has meant that the VBC has been able to be copied and used by other interested groups from a variety of countries and disciplines. One of the midwifery educators who was involved in the project subsequently moved to a new position and institution, and the licensing arrangements that were put in place have granted her the ability to copy the VBC to a new site and continue to develop the resources for use in another midwifery program.

OERs were identified in the 2009 Australia-New Zealand Horizon Report (Johnson, Levine, Smith, Smythe \& Stone, 2009) as being likely to have a significant impact on higher education within two to three years after the time of writing of the report. Rising costs associated with developing teaching and learning resources, together with pressures on educators' time, make OER an attractive option for promoting sustainability (Organisation for Economic Co-operation and Development [OECD], 2007). The development of teaching and learning strategies in MUVEs can be expensive and time consuming, and significant efficiencies can be achieved through the sharing of resources. However, analysis has shown that while educators are motivated to create their own OERs, they are less likely to reuse OERs that have been developed by others. When Duncan (2009) examined the Connexions OER repository (http://www.cnx.org/) at Rice University in the USA, for example, he found that only about $25 \%$ of the material in the repository was being reused. This reluctance to reuse others' resources is often attributed to the fact that it is too expensive and time consuming to appropriate or adapt materials developed for a different context, as well as to concerns about the quality of the materials (De Liddo, 2010). The sharing and reuse of resources is a feature of much of the work addressing sustainability of elearning, particularly in the UK (Attwell, 2004; Chatterton, 2011), and large-scale initiatives such as national learning object repositories have been developed (Attwell, 2004).

The resource-intensive nature of developing and maintaining educational resources in MUVEs lends itself to inter-institutional cooperation and resource sharing. Salmon (2005) recognises collaborations and consortia as useful ways to explore innovations that are relatively low-risk for the institutions concerned. The development of resources such as the VBC may be beyond the capacity of a single institution, and better shared by several. This may be especially true for institutions that do not have an existing MUVE presence. In an ideal world, we would like to see the VBC supported by a number of institutions that share in the use of the resource and the costs associated with continuing maintenance and development. Cooperation and collaboration within and between institutions is seen as vital to sustainability, especially in the OER and open-source movements (OECD, 2007). This having been said, competition for market share, research or innovation kudos and academic rivalries often stand in the way of institutions working together (Littlejohn, 2003). While inter-institutional collaboration is not without its challenges, in small programs such as midwifery that tend to be more boutique than large scale, there is much to recommend such an approach (see Tynan, Dunne \& Smyth, 2007). 


\section{Focussing on sustainability}

The development of MUVE-based teaching and learning resources and strategies tends to be even more demanding than other forms of e-learning development in terms of the time, money and expertise required. Educational institutions must find ways to be efficient in order make the most of limited and often scant resources. Sustainability should therefore be treated as a central issue to which attention is paid from the outset - that is, in the planning stages - of any project. This was perhaps the greatest weakness of the VBC project.

While innovations such as the VBC are often dependent on external funding for their development, sources and factors from within the institution will be responsible for their sustenance. These include organisational leadership, the provision of ongoing practical support, motivation and commitment of staff, and integration of the innovation within existing processes or strategies. While individual champions may be critical to an innovation's success, we can and should anticipate that such individuals will move on from their current positions, and we need to consider how the initiative can be sustained beyond the stewardship of those individuals.

Frameworks like Callan and Bowman's (2010a) may be useful to developers in the planning phases of a project in the way of assisting and prompting them to consider relevant issues impacting on sustainability. In order to maximise gains from scant resources, it may be wise for funding bodies to focus more intently on issues of sustainability, incorporating these into the criteria that they use to assess applications they receive for funding.

\section{Conclusion}

The Virtual Birth Centre (VBC) is an innovative teaching and learning resource or 'build' developed in the 3D multi-user environment of Second Life. Despite the devotion of considerable funds, time and expertise and the sharing of all resources by a project team that embraced an open-education philosophy, the VBC sits unused for the most part on its original site in Second Life. In this article, we have reflected on the factors impacting on the sustainability of the VBC using a framework developed by Callan and Bowman (2010b). While the VBC project enjoyed strong leadership from the project team, it was not incorporated as part of the overall e-learning strategy of the institutions in which it was pilot tested. Local e-champions were critical to the project, but heavy reliance on these individuals without the embedding of the resource within the relevant program meant that momentum and interest in the project died down when the e-champions left the particular school/department or institution.

For projects such as these, seed or innovation funding is important, yet in the absence of continued commitment from the institutions involved they are unlikely to be amply maintained or developed on an ongoing basis. Projects like the VBC often bring together unlikely partners (midwives and IT specialists, for example), and successful collaboration between those partners necessitates a degree of generosity along with open and effective lines of communication, because each party needs to understand elements of the other's expertise. The paucity of empirical evidence supporting claims about the effectiveness of MUVEs for teaching and learning is a persistent barrier to the sustainability of innovations in this area, since educators are limited in their ability to build a strong business case without such evidence. While the open sharing of 
resources associated with this project have contributed in a small way to the MUVE endeavours of other educators, this seems like a small return for the relatively sizeable investment that was expended on the development of the VBC.

There are a number of key issues for practice, policy and future research arising from our critical reflection on the sustainability of the VBC. First is the need for empirical studies to inform our understanding of teaching and learning strategies in MUVEs. Secondly, the importance and benefits of resource sharing and inter-institutional collaboration on MUVE-based teaching and learning initiatives (at both a national and international level) should not be overlooked. Thirdly and lastly, our experiences with the VBC have underscored the fact that a strategy for ensuring sustainability should be established in the planning stages of any MUVE-based education initiative; it cannot and must not be dealt with as an afterthought, or worse still, left to chance.

\section{Acknowledgments}

The authors would like to thank the SLENZ team, as well as the staff and students of Otago Polytechnic and Christchurch Polytechnic Institute of Technology who participated in the project. Funding for the project was provided by the New Zealand Tertiary Education Commission.

\section{References}

Andrews, T., Smyth, R., Tynan, B., Vale, D. \& Caladine, R. (2008). Rich media technologies and uncertain futures: Developing sustainable, scalable models. In Hello! Where are you in the landscape of educational technology? Proceedings ascilite Melbourne 2008 (pp. 36-40). Melbourne: Deakin University. http:/ / www.ascilite.org.au/conferences/melbourne08/ procs/andrews.pdf

Attwell, G. (2004). E-learning and sustainability. Report for the European Commission Lefo Learning Folders project. Pontypridd, UK: Pontydysgu. http:/ / www.guidanceresearch.org/knownet/ writing/papers/sustainabilitypaper/attach/sustainibility4.doc.pdf [viewed 29 Feb 2012]

Australia's Health Workforce Online (2010). National Health Workforce Taskforce. http: / / www.ahwo.gov.au/nhwt.asp [viewed 16 Oct 2011]

Bailey, J. (2012). The age of virtual learning. Midwives, 2012(1), 34-35. http: / / www.rcm.org.uk/midwives / features/the-age-of-virtual-learning/

Beard, L., Wilson, K., Morra, D. \& Keelan, J. (2009). A survey of health-related activities on Second Life. Journal of Medical Internet Research, 11(2). http: / / dx.doi.org/10.2196/jmir.1192

Birch, L., Jones, N., Doyle, P. M., Green, P., McLaughlin, A., Champney, C., ... Taylor, K. (2007). Obstetric skills drills: Evaluation of teaching methods. Nurse Education Today, 27(8), 915-922. http: / / dx.doi.org/10.1016/j.nedt.2007.01.006

Blyth, P., Loke, S. K. \& Swan, J. (2010). Otago Virtual Hospital: Medical students learning to notice clinically salient features. In Curriculum, technology $\mathcal{E}$ transformation for an unknown future. Proceedings ascilite Sydney 2010 (pp. 108-112).

http: / / www.ascilite.org.au/conferences / sydney10/procs / Blyth-concise.pdf

Boulos, M. N. K., Hetherington, L. \& Wheeler, S. (2007). Second Life: An overview of the potential of 3-D virtual worlds in medical and health education. Health Information and Libraries Journal, 24(4), 233-245. http: / / dx.doi.org/10.1111/j.1471-1842.2007.00733.x 
Bower, M., Kennedy, G. E., Dalgarno, B. \& Lee, M. J. W. (2011). Uniting on-campus and distributed learners through media-rich synchronous tools: A national project. In Changing demands, changing directions. Proceedings ascilite Hobart 2011 (pp. 150-155). Hobart: University of Tasmania.

http: / / www.ascilite.org.au/conferences/ hobart11/ downloads / papers / Bower-concise.pdf

Callan, V. \& Bowman, K. (2010a). Sustaining e-learning innovations: Literature review. Brisbane: Australian Flexible Learning Framework. [viewed 16 Oct 2011] http: / / www.flexiblelearning.net.au/files /Sust\%20Innov_1_Lit\%20rev_FINAL_1011.pdf

Callan, V. \& Bowman, K. (2010b). Sustaining e-learning innovations: A review of the evidence and future directions. Brisbane: Australian Flexible Learning Framework. [viewed 16 Oct 2011] http: / / www.flexiblelearning.net.au/files/Sust\%20Innov_Final\%20report_FINAL_1011.pdf

Chatterton, P. (2011). Sustaining and embedding innovations: Good practice guide. https: / / sustainembed.pbworks.com/ [viewed 5 Mar 2012]

Creative Commons (n. d.). Attribution-ShareAlike 3.0 New Zealand (CC BY-SA 3.0). http:/ / www.creativecommons.org/licenses/by-sa/3.0/nz / [viewed 5 Mar 2012]

Dalgarno, B. \& Lee, M. J. W. (2010). What are the learning affordances of 3-D virtual environments? British Journal of Educational Technology, 40(6), 10-32. http: / / dx.doi.org/10.1111/j.1467-8535.2009.01038.x

Dalgarno, B., Lee, M. J. W., Carlson, L., Gregory, S. \& Tynan, B. (2011a). An Australian and New Zealand scoping study on the use of 3D immersive virtual worlds in higher education. Australasian Journal of Educational Technology, 27(1), 1-15. http: / / www.ascilite.org.au/ajet/ajet27/dalgarno.html

Dalgarno, B., Lee, M. J. W., Carlson, L., Gregory, S. \& Tynan, B. (2011b). Institutional support for and barriers to the use of 3D immersive virtual worlds in higher education. In Changing demands, changing directions. Proceedings ascilite Hobart 2011 (pp. 316-330). Hobart: University of Tasmania. http: / / www.ascilite.org.au / conferences/ hobart11/ downloads / papers / Dalgarno-full.pdf

De Liddo, A. (2010). From open content to open thinking. In J. Herrington \& B. Hunter (Eds), Proceedings of World Conference on Educational Multimedia, Hypermedia and Telecommunications 2010 (pp. 3178-3183). Chesapeake, VA: Association for the Advancement of Computers in Education. http:/ / www.editlib.org/p/35094

Dow, A. (2008). Clinical simulation: A new approach. British Journal of Midwifery, 16(2), 94-98. http: / / www.intermid.co.uk / cgi-bin / go.pl/library / article.cgi?uid=28340;article=BJM_16_2_94_98

Duncan, S. (2009). Patterns of learning object reuse in the Connexions Repository. [viewed 16 Oct 2011]. http:/ / www.archive.org/details / PatternsOfLearningObjectReuseInTheConnexionRepository

Eley, R., Fallon, T., Soar, J., Buikstra, E. \& Hegney, D. (2008), The status of training and education in information and computer technology of Australian nurses: A national survey. Journal of Clinical Nursing, 17(20), 2758-2767. http:/ / dx.doi.org/10.1111/j.13652702.2008.02285.x

Fahy, K., Foureur, M. \& Hastie, C. (2008). Birth territory and midwifery guardianship: Theory for practice, education and research. Philadelphia: Books for Midwives.

Gunn, C. (2011). Sustaining elearning innovations. In Changing demands, changing directions. Proceedings ascilite Hobart 2011 (pp. 509-519). Hobart: University of Tasmania. http: / / www.ascilite.org.au/conferences/hobart11/ downloads/ papers / Gunn-full.pdf 
Haigh, J. (2007). Expansive learning in the university setting: The case for simulated clinical experience. Nurse Education in Practice, 7(2), 95-102. http: / / dx.doi.org/10.1016/j.nepr.2006.04.013

Hansen, M. M. (2008). Versatile immersive, creative and dynamic virtual 3-D healthcare learning environments: A review of the literature. Journal of Medical Internet Research, 10(3). http: / / dx.doi.org/10.2196/jmir.1051

Holt, D. \& Segrave, S. (2003). Creating and sustaining quality e-learning environments of enduring value for teachers and learners. In Interact, integrate, impact. Proceedings ASCILITE Adelaide 2003 (pp. 226-235). Adelaide: The University of Adelaide.

http: / / www.ascilite.org.au/conferences/adelaide03/docs/pdf/226.pdf

Holtham, C. (2005). Teaching and learning champions: An institutional perspective from the UK. Paper presented at the Society for Teaching and Learning in Higher Education Annual Conference, Charlottetown, Canada. [viewed 29 Feb 2012]

http: / / www.mcmaster.ca/stlhe/3M.council/Clive\%20Holtham.pdf

Honey, M. L. L., Diener, S., Connor, K., Veltman, M. \& Bodily, D. (2009). Teaching in virtual space: An interactive session demonstrating Second Life simulation for haemorrhage management. In Same places, different spaces. Proceedings ascilite Auckland 2009 (pp. 1222-1224). Auckland: The University of Auckland and Auckland University of Technology. http: / / www.ascilite.org.au/conferences/auckland09/procs/honey-interactivesession.pdf

Johnson, L., Levine, A., Smith, R., Smythe, T. \& Stone, S. (2009). The Horizon Report: 2009 Australia-New Zealand Edition. Austin, TX: The New Media Consortium. http: / / www.nmc.org/pdf/ 2009-Horizon-Report-ANZ-Edition.pdf [viewed 16 Oct 2011]

Johnson, C. M., Vorderstrasse, A. A. \& Shaw, R. (2009). 3D virtual worlds for health and healthcare. Journal of Virtual Worlds Research, 2(2), 3-12.

https: / / journals.tdl.org/jvwr/ article/ download/699/ 498

Kelly, O., Coburn, D., Hegarty, B., Jeffrey, L. \& Penman, M. (2009). Don't dilly dally on the way: Driving towards digital information literacy capability. In Same places, different spaces. Proceedings ascilite Auckland 2009 (pp. 519-523). Auckland: The University of Auckland and Auckland University of Technology.

http: / / www.ascilite.org.au/conferences/ auckland09/procs/kelly-o.pdf

Kessler, G. \& Rowell, J. (1998). Virtual medical symposia: Communicating globally quickly and economically. Medical Marketing \& Media, 33(9), 60-64.

Kirriemuir, J. (2010a). UK university and college technical support for Second Life developers and users. Educational Research, 52(2), 215-227. http: / / dx.doi.org/ 10.1080 / 00131881.2010.482756

Kirriemuir, J. (2010b). Virtual world activity in UK universities and colleges: 'What now?'. Snapshot \#9: Summer 2010. Birmingham, UK: Virtual World Watch.

http: / / www.virtualworldwatch.net/vww / wp-content/ uploads / 2011/09/Snapshot-9.pdf [viewed 29 Feb 2012]

Lathrop, A., Winningham, B. \& VandeVusse, L. (2007). Simulation-based learning for midwives: Background and pilot implementation. Journal of Midwifery \& Women's Health, 52(5), 492-498. http:/ / onlinelibrary.wiley.com/ doi/10.1016/j.jmwh.2007.03.018/abstract

Leap, N. (2002). Identifying the midwifery practice component of Australian midwifery education programs. Results of the Australian Midwifery Action Project (AMAP) Education Survey. The Australian Journal of Midwifery, 15(3), 15-23. http: / / dx.doi.org/10.1016/S1031$170 \times(02) 80004-6$ 
Leap, N., Barclay, L. \& Sheehan, A. (2003). Results of the Australian Midwifery Action Project Education Survey. Paper 2: Barriers to effective midwifery education as identified by midwifery course coordinators. Australian Midwifery, 16(3), 6-11. http: / / dx.doi.org/10.1016/S1448-8272(03)80010-X

Lee, M. J. W., Dalgarno, B., Gregory, S., Carlson, L. \& Tynan, B. (2011). How are Australian and New Zealand higher educators using 3D immersive virtual worlds in their teaching? Paper presented at the DEHub and ODLAA Education Summit 2011-2021, 15-18 February, Sydney.

Littlejohn, A. (2003). Supporting sustainable e-learning. ALT-J, Research in Learning Technology, 11(3), 88-102. http: / / dx.doi.org/10.1080/0968776030110308

Lok, B., Ferdig, R. E., Raij, A., Johnsen, K., Dickerson, R., Coutts, J., ... Lind, D. S. (2006). Applying virtual reality in medical communication education: Current findings and potential teaching and learning benefits of immersive virtual patients. Virtual Reality, 10(3-4), 185-195. http: / / dx.doi.org/10.1007/ s10055-006-0037-3

Lucas, B. (2006). Bringing e-learning home: An experiment in embedding e-learning using departmental e-learning advocates. In Who's learning? Whose technology? Proceedings ascilite Sydney 2006 (pp. 479-482). Sydney: The University of Sydney.

http: / / www.ascilite.org.au/conferences / sydney06/proceeding/pdf_papers/p101.pdf

Marginson, S. (2006). Dynamics of national and global competition in higher education. Higher Education, 52(1), 1-39. http:/ / dx.doi.org/10.1007/s10734-004-7649-x

McCallum, J., Ness, V. \& Price, T. (2011). Exploring nursing students' decision making skills whilst in a Second Life clinical simulation laboratory. Nurse Education Today, 31(7), 699-704. http: / / dx.doi.org/10.1016/j.nedt.2010.03.010

McGilvray, A. (2011). Student increase causes training bottleneck. Nursing Review. http: / / www.nursingreview.com.au / pages / section/ article.php?s=News\&idArticle=22327

Midwifery Council of New Zealand (2010). Competencies for entry to the register of midwives. http: / / www.midwiferycouncil.health.nz / images / stories / pdf / competencies $\% 20$ for $\% 20 \mathrm{entr}$ y $\% 20$ to $\% 20$ the $\% 20$ register $\% 20$ of $\% 20$ midwives $\% 202007$.pdf [viewed 16 Oct 2011]

New Zealand College of Midwives (n. d.). Standards for practice. http: / / www.midwife.org.nz/index.cfm/1,181,html [viewed 16 Oct 2011]

Oliver, M. (2010). "Everything I need to know I learnt from World of Warcraft": Why we might need to start asking better questions about games, simulations and virtual worlds. Keynote presentation ascilite Sydney 2010, Sydney, 5-8 December. http: / / www.slideshare.net/MartinOliver/ ascilite-2010-keynote [viewed 29 Mar 2012]

Organisation for Economic Co-operation and Development (2007). Giving knowledge for free: The emergence of open educational resources. Paris: OECD. [viewed 16 Oct 2011] http: / / www.oecd.org/ dataoecd/35/7/38654317.pdf

Rogers, L. (2011). Developing simulations in multi-user virtual environments to enhance healthcare education. British Journal of Educational Technology, 42(4), 608-615. http: / / dx.doi.org/10.1111/j.1467-8535.2010.01057.x

Salmon, G. (2005). Flying not flapping: A strategic framework for e-learning and pedagogical innovation in higher education institutions. ALT-J, Research in Learning Technology, 13(3), 201218. http:/ / dx.doi.org/10.1080/09687760500376439 
Salt, B., Atkins, C. \& Blackall, L. (2008). Engaging with Second Life: Real education in a virtual world. Literature review. [viewed 16 Oct 2011]

http:/ / slenz.files.wordpress.com/2008/12/ slliteraturereviewa1.pdf

Seropian, M. A., Brown, K., Gavilanes, J. S. \& Driggers, B. (2004). Simulation: Not just a manikin. Journal of Nursing Education, 43(4), 164-169.

http: / / www.slackjournals.com/article.aspx?rid=35108

Skiba, D. J. (2007). Nursing Education 2.0: Second Life. Nursing Education Perspectives, 28(3), 156157. http:/ / nlnjournals.org/doi/pdf/10.1043/10942831(2007)28\%5B156:NESL\%5D2.0.CO\%3B2

Slater, M., Linakis, V., Usoh, M. \& Kooper, R. (1996). Immersion, presence, and performance in virtual environments: An experiment with tri-dimensional chess. In M. Green (Ed.), Proceedings of the Third ACM Symposium on Virtual Reality Software and Technology (pp. 163172). New York: Association for Computing Machinery.

Stewart, S. (2006). Delivering the goods: Midwives' use of the Internet. In M. Murero \& R. E. Rice (Eds), The Internet and health care: Theory, research, and practice (pp. 177-194). Mahwah, NJ: Erlbaum.

Stewart, S. \& Davis, D. (2009, 22 Sep). Using a virtual birth unit to teach midwifery students. Paper presented at the 16th National Conference of the Australian College of Midwives, Adelaide. http: / / www.slideshare.net/ sarahs / using-a-virtual-birth-unit-to-teach-students [viewed 16 Oct 2011]

Tracy, S., Barclay, L. \& Brodie, P. (2000). Contemporary issues in the workforce and education of Australian midwives. Australian Health Review, 23(4), 78-88.

http: / / www.publish.csiro.au/ ?act=view_file\&file_id=AH000078a.pdf

Tynan, B., Dunne, K. \& Smyth, R. (Eds) (2007). Collaborating to offer small courses/subjects forum: Final report. Sydney: Carrick Institute for Learning and Teaching in Higher Education. http: / / www.olt.gov.au/system/files/resources/grants_report_smallcourses_feb08.pdf [viewed 26 Mar 2012]

Tynan, B. \& Lee, M. J. W. (2009). Tales of adventure and change: Academic staff members' future visions of higher education and their professional development needs. On the Horizon, 17(2), 98-108. http:/ / dx.doi.org/10.1108/10748120910965485

Wiecha, J., Heyden, R., Sternthal, E. \& Merialdi, M. (2010). Learning in a virtual world: Experience with using Second Life for medical education. Journal of Medical Internet Research, 12(1). http:/ / dx.doi.org/10.2196/jmir.1337

Wiles, K. \& Littlejohn. A. (2003). Supporting sustainable e-learning: A UK national forum. In Interact, integrate, impact. Proceedings ASCILITE Adelaide 2003 (pp. 730-734). Adelaide: The University of Adelaide.

http:/ / www.ascilite.org.au/conferences/adelaide03/docs/pdf/730.pdf

Winter, M. (2010). Second Life Education in New Zealand: Evaluation research final report. Christchurch, New Zealand: CORE Education. [viewed 16 Oct 2011] http: / / slenz.files.wordpress.com/2010/03/slenz-final-report-_milestone-2_-080310cca.pdf

Witmer, B. G. \& Singer, M. J. (1998). Measuring presence in virtual environments: A presence questionnaire. Presence: Teleoperators and Virtual Environments, 7(3), 225-224. http: / / dx.doi.org/10.1162/105474698565686 
Yellowlees, P. \& Cook, J. (2006). Education about hallucinations using an Internet virtual reality system: A qualitative survey. Academic Psychiatry, 30(6), 534-539.

http:/ / dx.doi.org/10.1176/appi.ap.30.6.534

Yu, S., Chen, I.-J., Yang, K.-F., Wang, T.-F. \& Yen, L.-L. (2007). A feasibility study on the adoption of e-learning for public health nurse continuing education in Taiwan. Nurse Education Today, 27(7), 755-761. http:/ / dx.doi.org/10.1016/j.nedt.2006.10.016

Authors: Sarah Stewart, Educational Developer

Educational Development Centre, Otago Polytechnic

Forth Street, Private Bag 1910, Dunedin 9054, New Zealand

Email: sarah.stewart@op.ac.nz Website: http:/ / sarah-stewart.blogspot.com/

Professor Deborah Davis, Clinical Chair in Midwifery

Faculty of Health, University of Canberra, ACT 2601, Australia

Email: deborah.davis@canberra.edu.au

Please cite as: Stewart, S. \& Davis, D. (2012). On the MUVE or in decline: Reflecting on the sustainability of the Virtual Birth Centre developed in Second Life. In M. J. W. Lee, B. Dalgarno \& H. Farley (Eds), Virtual worlds in tertiary education: An Australasian perspective. Australasian Journal of Educational Technology, 28(Special issue, 3), 480-503. http:/ / www.ascilite.org.au/ajet/ajet28/stewart.html 